\title{
The evolution of human anatomy in India
}

\begin{abstract}
Anatomy has been a cornerstone of medical education for hundreds ofyears. But lately, over the last fewyears, Anatomy in undergraduate education has been undergoing a lot changes. Methods of teaching, methods of assessment, methods of cadaver procurement, embalming methods etc. all have undergone metamorphosis. Not only that, the tenure of the curriculum is on the decline, thus resulting in the course content also being on the decline. So who says Anatomy is always constant and can never change? We conducted a survey among the students to gauge their views regarding the changes in anatomy which had taken place over theyears and also their opinion regarding load of study in the short time span. We came to the conclusion that changes in Anatomy should be such that it should be clinically relevant for specialists to practice safely in the future and to provide a strong base for future clinical developments. This review focuses on how the study of anatomy in India has evolved through the centuries.
\end{abstract}

Keywords: anatomy, medical education, undergraduate, methods of teaching, methods of assessment, methods of cadaver procurement, embalming methods, constant, change
Volume 4 Issue 2 - 2017

\author{
Sharadkumar Pralhad Sawant, Shaheen Rizvi \\ Department of Anatomy, KJ Somaiya Medical College, India
}

Correspondence: Sharadkumar Pralhad Sawant, 25/2, Samrat Ashok Nagar Society, Shell Colony Road, Chembur, Mumbai-400 07I, Maharashtra, India, Tel 932206I 220, 02222925745, Fax 022 2409 1855, Email drspsawant@gmail.com

Received: March 18, 2017| Published: September 18, 2017

\section{Introduction}

\section{History of anatomy in India}

Anatomy is the oldest and the most important of all medical sciences. Anatomical knowledge in ancient India was derived principally from the sacrifice of animals, by chance observations of improperly buried bodies, and examinations of patients by physicians. ${ }^{1}$ Archeological excavations from Indus valley civilization period show cave paintings depicting pictures of animals on which those critical areas are marked which when hit would have killed the animals. This is clear evidence of first lessons in surface anatomy. The Vedas referred to heart as "Lotus with nine gates", an amazingly accurate description of the heart as we know it today. If the heart is held with its apex upwards, there are nine openings in all-3 in the night atrium, 4 in the left atrium and one each in the right and left ventricles, it indeed looks like a lotus bud. There is an accurate description of the embryo in the Upanishad, which predates microscopes. It is truly amazing, as it matches almost accurately with the present-day knowledge of embryology. For e.g in the Upanishads it is written that seven nights after intercourse, the embryo becomes a vesicle - 'Budbuda'. Seven days old embryo is indeed vesicular and is called blastocyst today.

The post-upanishadic period is considered the "The Golden Age of Indian Medicine". Ayurveda, the science of life (Ayur=long life; Veda=science) was evolved during this period by two great proponents -Susruta and Charaka. In Susruta's work, it is evident that considerable thought was given to anatomical structure and function, as Susruta was a proponent of human dissection; ${ }^{2}$ his texts include a systematic method for the dissection of the human cadaver. In the Sanskrit writings of Susruta samhita, there is a complete section "Sarira sthana" devoted to Anatomy. Besides gross anatomy, embryology and histology are also dealt with, which indicate a comprehensive study of Anatomy. ${ }^{3}$ The Sarira-sthaka discusses mainly anatomy, embryology and technique of dissection. During this period the ancient Indians also pioneered in human dissection. Susruta gave the number of bones and muscles of the body. He described blood vessels, 4 pairs of cranial nerves, lungs, stomach, intestines, bladder, uterus and rectum.
He even described the joints and the effects of their injuries. Susruta aptly called as "The father of Surgery" and can easily be also named as "The father of applied anatomy".

Under the British rule, medical schools were established in the late 19th century in the metropolitan towns of Madras, Calcutta and Bombay. The Madras Medical College opened in 1835, and admitted women so that they could treat the female population who traditionally shied away from medical treatments under qualified male professionals. Dr. Mortimer of Madras used to teach the students, muscles and bones from paste-board models. He framed a text book in Practical Anatomy "Mortimer's Manual of Anatomy."This manual precedes "Cunningham's Manual of practical Anatomy." Before 1900, there were only three medical colleges, at Madras, Calcutta, and Bombay. Today there are 335 recognized medical colleges (2011) with 40525 undergraduate seats and all of them have a full-fledged department of anatomy where manual dissection is done and taught. ${ }^{4}$

Lack of uniformity in the standards of teaching anatomy in different institutions gave the impetus to start a common platform to discuss and decide the academic aspects. Thus was born "Anatomical Society of India"- ASI on 20th May 1951. The main objective of the society was the advancement of study and research in Anatomy. It was also decided to bring out a journal under the aegis of the society. The journal 'Journal of Anatomical Society of India' which began as a humble publication, has metamorphosed into an indexed journal that promotes online education in Anatomy at firstprofindia@ yahoogroups.com. ${ }^{5}$

Thus in India the science of Anatomy has valiantly climbed the steps of time having been taught and practiced from the pre-Vedic period to the present era of online education on computers and it is sure to go on to achieve greater strides in future.

\section{Material and methods}

A survey was conducted at K.J. Somaiya Medical College in the month of Dec 2014. A structured questionnaire was prepared. Adequate explanation was given to the students about the objectives 
of the study before they filled out the questionnaire and verbal consent was obtained. They were assured of confidentiality and their names were not recorded to keep anonymity. First year undergraduate medical students who were studying Anatomy and those students who had just finished Anatomy and joined second year were included in the study. In all 100 students participated. The questionnaires were designed to collect information regarding students' awareness about the history of Anatomy, the various methods of teaching and their preference, the assessment methods; whether they were aware about how cadavers were procured and how they were embalmed. Their awareness was also sought regarding latest museum techniques and histology techniques. We also enquired from them regarding the load of study in the first year and whether the time span allotted to them was enough for study.

\section{Observations}

The results of the questionnaire were compiled. It was observed that only $30 \%$ of the students were aware of the history of Anatomy, $65 \%$ of the students were not aware of the history of Anatomy and $5 \%$ of the students had never heard about the history. Regarding teaching methodologies, $70 \%$ of the students preferred chalk and board method of teaching, 25\% preferred Power point presentations and around 15\% preferred a combination of both methods.

$80 \%$ of the students felt that dissection was the best method of learning Anatomy, but $90 \%$ of the students were not aware about cadaver procurement and only about $15 \%$ students had a very vague idea of how cadavers were embalmed. Many were not even aware about the spelling of embalming. None of the students were aware about the latest museum techniques in Anatomy.

Regarding Histology techniques, the students were only too happy about having to study only about two stains-the Haemotoxylin and Eosin. They had never heard about special stains and were glad about them not being used.

All the students were very happy about the present assessment methods as there were not only objective type questions in the paper, but also 20 viva marks were included in the theory, which helped to raise their overall percentages.

\section{Discussion}

\section{Methods of teaching anatomy}

In the early days of medical education, the study of gross anatomy was based on cadaveric dissection to such an extent that it was almost revered as 'the very essence of Anatomy'. This was so because it was the only method of understanding the 3-dimensional structure of the human body. In the 19th century, India was under the British rule. According to the British, 'The basis of all medical and surgical knowledge is anatomy ... there can be no rational medicine, and no safe surgery, without a thorough knowledge of anatomy'. To the Indian people, especially Hindus, touching the dead body is an abominable question, better not to say anything of dissection. But, on entering Medical College, Madhusudan Gupta was the first amongst the Hindus to be engaged in the act of dissection. Madhusudan Gupta (1800-1856) is almost without exception given the credit of the first dissector (dissection on 10 January 1836). It was also Asia's first human dissection. His precedence encouraged other Hindus. Dissection of a cadaver by any high-caste Indian was the first phenomenal step in the direction of modern medical education. The practice of dissection since then advanced so rapidly that practical anatomy became a portion of the necessary studies of the Hindu medical students as amongst their brethren in Europe and America. ${ }^{6}$

Today the new medical curriculum includes clinical reasoning, physical examination skills, problem based learning, radiological imaging and computer simulations. The availability of innovative methods of teaching-learning anatomy such as interactive multimedia resources, live body scans, virtual 3 dimensional images as well as plastic models have not diminished the importance of dissection in the eyes of the medical students. They consider dissection to be indispensible to the study of human gross anatomy. Dissection has survived the most rigorous test - the test of time and is still followed in all colleges of India as one of the teaching methods for anatomy.

Over theyears, the other traditional method of teaching gross anatomy has been the passive didactic lecture method using either OHP, Power point or conventional chalk and board. The current trend in medical education includes integrating basic science study with clinical subjects, so that the students learn the relevance of what they are studying.

There is also a shift from traditional "teacher centered learning" methods to "student centered learning" methods. Within studentcentered learning, a newer teaching modality called PBL (Problem based learning) has been developed. Evidence is available to show that knowledge retrieval is facilitated when knowledge is acquired in a situation resembling those in which it will be applied.

Tenure of the curriculum: Prior to 1997, the I MBBS consisted of $1 \frac{1}{2}$ years, but this was trimmed to make more time available for clinical exposure. The MCI has changed its regulations on graduate medical education in 2012. The duration of first year MBBS, has been condensed from one and a half year to 1year and in reality the students get just 8-9months. Thus the traditional anatomy education based on gross anatomy which was earlier taught by didactic lectures and complete dissection of the body has also been drastically reduced. Some topics like Genetics have been completely trimmed to about 8-10 lectures. Today there is a rapid expansion of knowledge in basic medical disciplines, requiring more teaching time, at the same time there is a strong tendency for curriculum reformers to reduce the teaching time. Within anatomy itself, there is a "competition for space and time" between recently introduced but quickly accepted perspectives (e.g., surface and imaging anatomy, applied and clinical anatomy and anatomical variations) that are becoming an integral part of the anatomy teaching. ${ }^{?}$

The outcome, due to the reduction of curriculum and time both, is also visible among the students. By the time students confirm their admissions, get adjusted and settle down into a new place, a considerable amount of time has elapsed. Majority of the students felt that the time allotted to cover such an immense portion wasn't adequate, they felt a scarcity of time. Hence the average students barely appreciate the relevance of what they are studying, in fact they are happy that the syllabus has reduced and in the end the main objective remains just to pass.

Student's preferences over teaching methodologies: In the earlyyears, there was only one methodology of teaching-chalk and Board. Traditionally, most of the lectures were taken with chalk and board $(\mathrm{C} \& \mathrm{~B})$ in India. With the advancement of technology and concurrent economic growth of India, the use of computer assisted techniques in teaching became inevitable. The use of power-point presentations (PPT) were increasingly adopted by many medical colleges. The young generation teachers are more fascinated by it. 
There came a time when some institutional heads started making using of PPT compulsory for the staff members. As a result, some of the teachers lost the curiosity and stopped taking the initiative of using chalk-board for teaching. Today few teachers use chalk and board.

Various researchers in the world have assessed the preferences amongst the students for these teaching tools. In majority of the studies as well as in our study, the students opined that in all parameters studied i.e. conceptual understanding, memorization and reproducibility of text information as well as diagrams in theory examination and viva, the $\mathrm{C} \& \mathrm{~B}$ was more helpful than the PPT. Hence what we find among the students is a preference for the traditional method of teaching, which has gained an upper hand over the modern teaching tools. Today in most of the medical colleges in India, although the use of PPT is not compulsory, very few teachers use the traditional chalk and board method of teaching. ${ }^{8}$

Cadaver procurement: Cadavers remain an important teaching method in gross anatomy. Knowledge obtained through dissection of human body is an indispensable part of education for medical professionals. In India, the Anatomy Act was enacted in 1949, which has been uniformly adopted in all states of the republic of India. It provides for the collection of a dead body for teaching purpose, only if death occurs in a state hospital or in a public place within the prescribed zone of medical institution, provided the police have declared a lapse of 48 hours, that there are no claimants for the body and it could be used for medical purpose. ${ }^{9}$ All cadavers which are accepted for medical education purposes, be it for dissection or research purpose, are all governed by the Anatomy Act of 1949, whether they are voluntary donations or unclaimed cadavers.

Initially the only source of cadaver procurement were unclaimed cadavers. But there were media reports on the sale of cadavers between medical colleges and police. ${ }^{9}$ Furthermore, for unclaimed cadavers, there would be a lot of running around at the police stations and a lot of paper work involved. Gradually unclaimed bodies ceased to be the source of cadaver procurement. Today unclaimed bodies are difficult to come by and are no more the origin of cadavers.

Nowadays the only source of cadaver procurement is voluntary body donation explicitly, based on altruistic reason, by the person him/ herself. It is the best morally accepted cadaver source for dissection. The motivation of such a gesture is strictly altruistic: training the future medical staff and contribution to the scientific progress.

Human cadavers for the purpose of study are a scarcity, with mushrooming of medical institutions in this country. Body donation is a generous and unselfish act for those who wish to be useful to the living after death. The donor will help the medical students for further learning and research. There is a need for creating an increased awareness of whole body donation. ${ }^{10}$

We Anatomists and thousands of medical students sincerely place our regards to hundreds of unknown dead people who taught us Anatomy by donating their bodies.

\section{Methods of embalming}

The main object of embalming is to prevent decomposition of cadavers, and to maintain a desired life-like appearance of the body which is non hazardous for dissection and environmentally safe. The embalming fluid consists of a group of chemicals that include preservatives, germicides, buffers, wetting agents, anticoagulants, dyes, perfuming agents, etc. These groups are combined in various proportions to produce the embalming fluid, the predominant chemical being formalin. Very often the cadavers embalmed by various chemicals are not effective in inhibiting growth of fungi, bacteria, maggots etc. Due to the presence of formaldehyde in the embalming fluid, chemical odour and eye irritations cause discomfort in the dissection room.

Nowadays there is a lot of research going on to create an embalming fluid which can include more salts and lesser amount of formalin so as to prevent the toxic effects of formalin. One such method is the Thiel method of soft embalming. It is a technique which relies on a mixture of salt compounds and very low amounts of volatile formaldehyde and formalin to effect fixation of tissue with a number of unique properties. Cadavers preserved with the Thiel Method have no detectable odour, a lifelike flexibility of body parts, excellent colour preservation of muscle, viscera, and vasculature, and superior antimicrobial preservation properties. Introduction of embalming fluid through the external iliac artery and drainage from the superior sagittal sinus spares the inferior neck and femoral triangle regions from damage during the embalming procedure. This procedure presents a number of significant educational advantages over traditional methods of embalming. Because of the more lifelike texture and colour of structures students' dissections are of high quality, thus improving learning. Appreciating the actions of muscles at joints, especially in the extremities, is facilitated by the flexibility of the cadaver. Teaching and learning clinical procedures, such as intubation, lumbar puncture, central line placement, thoracocentesis, and all fields of surgery, including pelvic floor repair and face lift are possible due to the softness of the cadaver. The flexibility of the peritoneal membrane and internal viscera allows soft-embalmed cadavers to be especially useful in teaching laparoscopic surgical anatomy. Soft embalming holds much promise for further innovative educational uses in cadaver-based anatomical and clinical instruction. ${ }^{11}$

Museum techniques: Specimens in Anatomy museum are mounted by various methods. Specimens are first fixed using Kaiserling's technique which has been in use foryears now. Organs with their attached vessels and excretory ducts are mounted on glass/acrylic plate/ and used X-Rays plate/plastic sheets. Initially specimens were mounted in cylindrical jars and sealed with sheep bladder walls. Later they were replaced by rectangular glass jars and covered with glass plates to afford a clearer view of the specimen. The jars were either purchased readymade or prepared in the museum itself. To support the specimen within the jar, it was attached to a specimen plate or to bent glass rods and was tied with nylon threads.

Nowadays glass jars have been replaced by Perspex jars as they are much lighter, break resistant and help to preserve the specimen better. They cannot be used for specimens fixed with alcohol or methyl salicylate as they react with them.

Museum specimens are generally mounted in glass jars or Perspex. A more feasible alternative now initiated is polyethylene terephthalate (PET, PETE or polyester) that is commonly used for carbonated beverage and water bottles. PET provides sufficient alcohol and essential oil barrier properties, generally good chemical resistance (although acetones and ketones will attack PET) and a high degree of impact resistance and tensile strength. These bottles are translucent, thin and inert, and can easily be cut with scissors or a blade in order to adapt properly to the size of the jar. PET sheets can be easily cut, sutured to the specimens (multiple if needed) and does not visually hinder the display. For a smaller jar, a hinge-like preparation of these plastic bottles gives a stable support to the specimen. The PET sheets used do not lose integrity, colour or contour for over a period of 12 months. ${ }^{12}$ 
For specimens which can get disfigured in the long run (e.g. soft tissues like brain) or face problems during stitching, sutures become too tight and cut through the specimen, or if they are loose, the tissue hangs on the plate and little bit of jerk can damage the specimen. A new method using Paraffin wax, has been tried with promising results. Paraffin wax which is used in the Histology Laboratory for making blocks, is used for mounting the specimen instead of the plastic sheet. It was found that this method is quite cheap, easy to use and can be repeated without any problem in case anything goes wrong. Relations are also better maintained. ${ }^{13}$

Plastination was invented in 1978 by Dr. Gunter Von Hagens. The principle of plastination involves removal of water and lipid from the tissues and their replacement by a plastic (curable polymer). Though expensive, plastinated specimens are individually superior to their counterparts both in terms of aesthetic superiority and in their demonstration of specific features. They also do not undergo significant deterioration over manyyears of continuous use. One of the most interesting, important and potentially useful qualities of tissue plastination by silicone, is that its microscopic structure remains intact. ${ }^{14}$

Histology techniques: Histology is the study of the microscopic details and structures of biological cells and tissues, using light, fluorescence or electron microscopes, examining a thin slice (called a "section") of tissues, that have been previously prepared using appropriate processes called "histological techniques". It is necessary to prepare histology slides of a sample or specimen and examine them first in order to find out if the cells or tissue are healthy or diseased. The first half of the 20th century was a very productive period for new staining techniques in histology and histopathology. Indeed the 1906 Nobel Prize in Physiology or Medicine was awarded to histologists Camillo Golgi and Santiago Ramon Cajal. They had conflicting interpretations of the neural structure of the brain based on differing interpretations of the same images. Cajal was appreciated for his correct theory and Golgi for the staining technique that he invented. In 1673 Anton van Leeuwenhoek developed a simple microscope with a single lense but with improved magnification and resolution. The first microtome suitable for sectioning animal tissues was constructed in 1848. During the 19th century paraffin wax was introduced for infiltration and support during sectioning. Formalin was first used as a fixative in 1893 and today is widely employed. In order to better underline different biological structures, histological stains are used to modify or enhance the colours of certain biological structures differently from the others, that may be located next to them or be in contact with them. There are many different histology stains selected according to the type of tissue to be observed. One of the oldest stains was Prussian blue, introduced in 1774. The hematoxylin and eosin staining techniques were first described in 1875-1878.

Hematoxylin and eosin (H\&E stain) are one of the oldest and the most commonly used histology stain for light microscopy. All the Histology slides taught to students till today, in undergraduate Anatomy curriculum are stained with Hematoxylin and eosin (except ground section of bone). Hematoxylin stains the nuclei within cells blue and eosin stains the cytoplasm of cells pink. H\&E is a permanent histology stain. ${ }^{15}$

\section{Methods of assessment}

In the earlyyears of medical education, initially there was a separate paper for Anatomy while Physiology and Biochemistry were combined. Later on Anatomy had two papers, Paper I and Paper II, and Physiology and Biochemistry separated out. Later, they also got converted to Paper I and Paper II. In the initial stages, Journal diagrams included not only Histology and gross anatomy, but also embryology and genetics and the journals carried marks. The theory papers included only subjective type questions, there were no viva marks added to theory and there was no internal assessment. In Maharashtra every district had its own university, so even in one state, there were various universities offering the degree of MBBS, so there was no uniformity in medical education.

Today all states of India have their own university. So at least within each state there is uniformity of medical education. In Maharashtra, we have a 'Maharashtra University of Health Sciences' which includes in Anatomy, two Theory papers of 50 marks each , Oral (Viva) 20 marks which gets added to theory, a 40 marks Practical examination and Internal Assessment of 40 marks (Theory-20; Practical-20). Student must secure at least $35 \%$ of the total marks fixed for internal assessment to be eligible to appear in final university examination of that subject. Recently a new system has been introduced by the university - A supplementary examination is held not later than 6months after the publication of the results of the regular batch so as to avoid the formation of a separate repeater batch. ${ }^{16}$

These assessment methods are very different from the earlier methods, in which passing would be tough for average students, leave alone scoring. These assessment methods of today, are just loved by the students, because not only is it difficult to fail today, but it is easy to score distinctions.

But the sad part of the Indian medical education scene is that, $\mathrm{MCI}$ does not cross-check the individual graduates before registration. There is no expulsion of students with repeated failures and every medical student becomes a doctor irrespective of theyears spent in the college or the skills learnt. Universities have no role in medical education except to conduct the examination and award degrees. Teachers deliver lectures and concentrate only on their subject. The students study before their examination with an aim to pass and qualify. Although external examiners are there, standards vary from center to center. ${ }^{17}$

\section{Post graduation in anatomy}

Earlier, post graduate degree in Anatomy was M.S, There were no entrance exams for admission to a postgraduate course. Also, there was no log book for the students to maintain and there was no preliminary examination before the Final exams. So obtaining a post graduate degree in Human Anatomy was relatively easier.

But now, rules and regulations regarding admission criteria have changed. So, even for admission to a preclinical postgraduate degree like Anatomy, a student will have to appear for an entrance exam which entails all the subjects studied in the MBBS course. Under the 'Maharashtra University of Health Sciences' (MUHS), the name of the degree has changed to M.D. The postgraduate students registered for an M.D in Human Anatomy, have to maintain a log book which contains all their academic activities during the 3 year course. They also have to face a preliminary examination before the final university examination.

\section{Conclusion}

So, who says anatomy never changes? As we have seen, Anatomy has undergone considerable changes, over theyears. Regarding the awareness level among the students, we feel that the students should be educated a little about the history of Anatomy, as well as about museum techniques and histology staining techniques. Majority 
of the students are happy with the assessment methods but are not very happy with the tenure of First MBBS course. PG students doing Anatomy are not happy with the present state of the PG course.

\section{Acknowledgements}

The authors wish to convey his sincere thanks to our Dean Dr. Geeta Niyogi Madam for her valuable help, support and inspiration. We are also thankful to Mr. M. Murugan. Authors also acknowledge the immense help received from the scholars whose articles are cited and included in references of this manuscript. The authors are also grateful to authors/editors/publishers of all those articles, journals and books from where the literature for this article has been reviewed and discussed.

\section{Competing interests}

The authors declare that they have no competing interest.

\section{Authors contributions}

SPS drafted the manuscript, performed the literature review \& SR assisted with writing the paper

\section{References}

1. Zysk KG. Religious Medicine. The History of India Medicine and Revolution. 7:75.

2. Persaud TVN. Early History of Human Anatomy. Illinois: Charles C Thomas, Springfield; 1984

3. Loukas M, Lanteri A, Ferrauiola J, et al. Anatomy in ancient India: a focus on the Susruta Samhita. J Anat. 2010;217(6):646-650.

4. Rajgopal L, Hoskeri GN, Bhuiyan PS, et al. History of anatomy in India. J Postgrad Med. 2002;48(3):243-245.
5. Patnaik VVG. Editorial. J Anat Soc India. 2002;50(2):143-144.

6. Jayanta Bhattacharya. The first dissection controversy: introduction to anatomical education in Bengal and British India. Current science. 2011;101(9):1227-1232.

7. BW Turney. Anatomy in a Modern Medical Curriculum. Ann R Coll Surg Engl. 2007;89(2):104-107.

8. Rokade SA, Bahetee BH. Shall we teach anatomy with chalk and board or power point presentations? - an analysis of Indian students' perspectives and performance. Sch J App Med Sci. 2013;1(6):837-842.

9. Subramanian BV. Law in relation to medical men In: Modi, editor. Medical Jurisprudence and Toxicology. 22nd ed. Butterworth, New Delhi, India; 1999. p. 724-727.

10. Rajkumari Ajita, Ibochouba Singh Y. Body: donation and its relevance in anatomy learning-a review. J Ant Soc India. 2007;56(1):44-47.

11. Thiel W. Annals of Anatomy. 1992;174:185-195.

12. Natarajan S, Ranjan J, Boaz K. Museum mounting techniques: Revisited econo-mode. Indian J Pathol Microbiol. 2012;55(2):260-261.

13. Virender Kumar Nim. Wax mounting of specimen in anatomy museum. J Anat Soc India. 2012;61(1):41-43.

14. Ravi SB, Bhat VM. Plastination: A novel, innovative teaching adjunct in oral pathology. J Oral Maxillofac Pathol. 2011;15(2):133-137.

15. Giuseppe Musumeci. Past, present and future: overview on histology and histopathology. Journal of Histology \& Histopathology. 2014.

16. ht t p : // w w w. m u h s.a c. i n / u p lo a d / s y 11 a bu s Phase1_060810_16082012_1233.pdf

17. Haranath PSRK. Integrated teaching in medicine-Indian scene. Indian J Pharmacol. 2013;45(1):1-3. 